\title{
Tuberculosis in Nunavut: a century of failure
}

\author{
Noni MacDonald MD MSc, Paul C. Hébert MD MHSc, Matthew B. Stanbrook MD PhD
}

I n 1911, when CMAJ began publishing, the seriousness of tuberculosis was such that CMAJ devoted six articles to the topic in its first volume. Among them was the journal's first editorial on tuberculosis, which prophetically noted the then-novel recognition of the role of childhood latent infection in later clinical disease. ${ }^{1}$

A century later, Nunavut has recorded the largest tuberculosis outbreak in the territory's 10year history. At least 100 new active cases were documented in 2010, a population rate 62 times the Canadian average. Worse still, the outbreak involves adolescents and young adults, a pattern consistent with active community transmission.

Proper public health measures are in place in Nunavut, but they are under-resourced. School children are screened in kindergarten, grade six and grade nine, and routine screening has been implemented in high-risk facilities such as homeless shelters and prisons. However, for the rest of the population, screening is implemented less successfully, particularly among young people who often have minimal contact with the health system. Directly observed therapy is used for active cases with high completion rates. At present, contact tracing is labour and resource intensive.

A substantial concern has been community mistrust, which is rooted in a historic legacy. Decades ago, the federal public health strategy, now recognized as misguided, was communitywide screening followed by forced deportation of residents south for treatment, often without their consent or any notice given to their families. Many died and many more never returned home. The ensuing mistrust of physicians and public health, combined with the stigma associated with tuberculosis, may still be hampering control efforts.

Geography as well as socioeconomic factors are important barriers to providing effective health services and public health interventions in Nunavut. Its communities are the smallest and most isolated of any jurisdiction in Canada. Nunavut residents also face high rates of poverty and unemployment and a lack of quality housing and community infrastructure - substantially more so than Canada's other arctic territories. Overcrowded houses with poor ventilation are the norm - conditions ideal for transmission of airborne infections like tuberculosis. Furthermore, many Nunavut residents smoke

or are exposed to high household concentrations of second-hand smoke. These factors, combined with poor nutrition and for some, misuse of alcohol or other substances, weaken the immune system's ability to control tuberculosis.

London, England is also experiencing the highest incidence of tuberculosis in Europe, concentrated in the poorly housed and the homeless. ${ }^{2}$ In both Nunavut and England, some common socioeconomic determinants prevail: poverty, poor nutrition, and, most important, a lack of adequate housing. ${ }^{2}$

In Canada, nothing will change without the federal and territorial governments coming together with Nunavut communities to address the current outbreak. Coordinated efforts have brought tuberculosis rates down in the Northwest Territories.

Nunavut itself can do more, but not enough with the resources at its disposal. There is a need to rebuild trust in public health through greater active community engagement and public education while being sensitive to cultural concerns. Greater resources should target increased access to diagnostic testing, treatments, contact tracing and more comprehensive screening programs. An immediate focus on improving substandard housing and overcrowding is critical to the success of any northern tuberculosis eradication strategy.

However, eradication of tuberculosis will require not only the implementation of immediate coordinated public health measures, but also longterm economic investments and growth to tackle poverty and poor housing. Although the Government of Canada's strategy provides hope for the people of the North, the eastern arctic would benefit from greater investments in health such as adequate housing, food security and paying jobs to ensure its long-term prosperity.

This is not just Nunavut's problem — it is Canada's problem. Collectively, we must find the will to deploy resources while remaining sensitive to historic and cultural concerns.

It's long past time that the people of Nunavut were freed from the "white plague."

\section{References}

1. The final report of the British Royal Tuberculosis Commission Can Med Assoc J 1911;1:978-82.

2. Zumla A. The white plague returns to London - with a vengeance. Lancet 2011;377:10-1.
Competing interests: See www.cmaj.ca/misc/edboard .shtml

Affiliations: Section Editor, Public Health (MacDonald) Editor-in-Chief (Hébert) and Deputy Editor, Scientific (Stanbrook), CMAJ

Correspondence to: $C M A J$ editor, pubs@cmaj.ca

CMAJ 2011. DOI:10.1503 /cmaj.110160 